\title{
Designer GPCRs as Novel Tools to Identify Metabolically Important Signaling Pathways
}

\author{
Jürgen Wess * \\ Molecular Signaling Section, Laboratory of Bioorganic Chemistry, National Institute of Diabetes and Digestive and Kidney \\ Diseases, Bethesda, MD, United States
}

Keywords: G protein-coupled receptors, G proteins, type 2 diabetes, obesity, mutant mouse models, DREADD technology, chemogenetics

\section{OPEN ACCESS}

Edited by:

Tobias Fromme,

Technical University of Munich,

Germany

Reviewed by:

Eugenia Gurevich,

Vanderbilt University, United States

*Correspondence:

Jürgen Wess

jurgenw@niddk.nih.gov

Specialty section:

This article was submitted to

Cellular Endocrinology,

a section of the journal

Frontiers in Endocrinology

Received: 08 May 2021

Accepted: 15 June 2021

Published: 20 July 2021

Citation:

Wess J (2021) Designer GPCRs as Novel Tools to Identify Metabolically Important Signaling Pathways.

Front. Endocrinol. 12:706957. doi: 10.3389/fendo.2021.706957
G-protein coupled-receptors (GPCRs) form a very large family of cell surface receptors that respond to an extraordinary variety of extracellular ligands and sensory stimuli (1). The human genome codes for $\sim 800$ distinct GPCR genes, representing $\sim 3-4 \%$ of all human genes (2). Approximately $1 / 3$ of all FDA-approved drugs act on one or more GPCRs, indicative of the enormous clinical relevance of this class of receptors (3). Upon binding of extracellular ligands, GPCRs activate distinct classes of heterotrimeric $G$ proteins, which are composed of four major subfamilies, $G_{s}, G_{i}, G_{q}$, and $G_{12}$ (heterotrimeric $\mathrm{G}$ proteins are named after the $\alpha$-subunits present in the heterotrimeric complex) (4). The receptor-activated $\alpha$-subunits then modulate the activity of distinct intracellular signaling pathways (4) (also see Figure 1).

Like all other cells, metabolically relevant cell types express dozens of different GPCRs (9). However, each individual GPCR is expressed by many other cell types and tissues (9). Moreover, agonist and/or antagonist ligands with high selectivity for a particular GPCR are not available in many cases. For these reasons, it has been very challenging to elucidate the in vivo metabolic roles of specific GPCR/G protein signaling pathways operative in a particular cell type.

To circumvent these obstacles, my lab, as well as other research groups, started to employ a chemogenetic approach involving the use of designer GPCRs known as DREADDs (designer receptors exclusively activated by a designer drug) (5). Structurally, the most commonly used DREADDs are mutant muscarinic acetylcholine receptors which, due to the presence of two point mutations in the transmembrane core, show little or no activity in the presence of acetylcholine, the endogenous muscarinic receptor agonist (Figure 1). However, muscarinic receptor-based DREADDs can be efficiently activated by a synthetic compound called clozapine- $\mathrm{N}$-oxide (CNO) $(5,6)$. CNO is otherwise pharmacologically inert, at least when used in the proper dose or concentration range. More recently, $\mathrm{CNO}$ derivatives with increased metabolic stability and improved pharmacokinetic properties have been described $(10,11)$. During the past 15 years, 

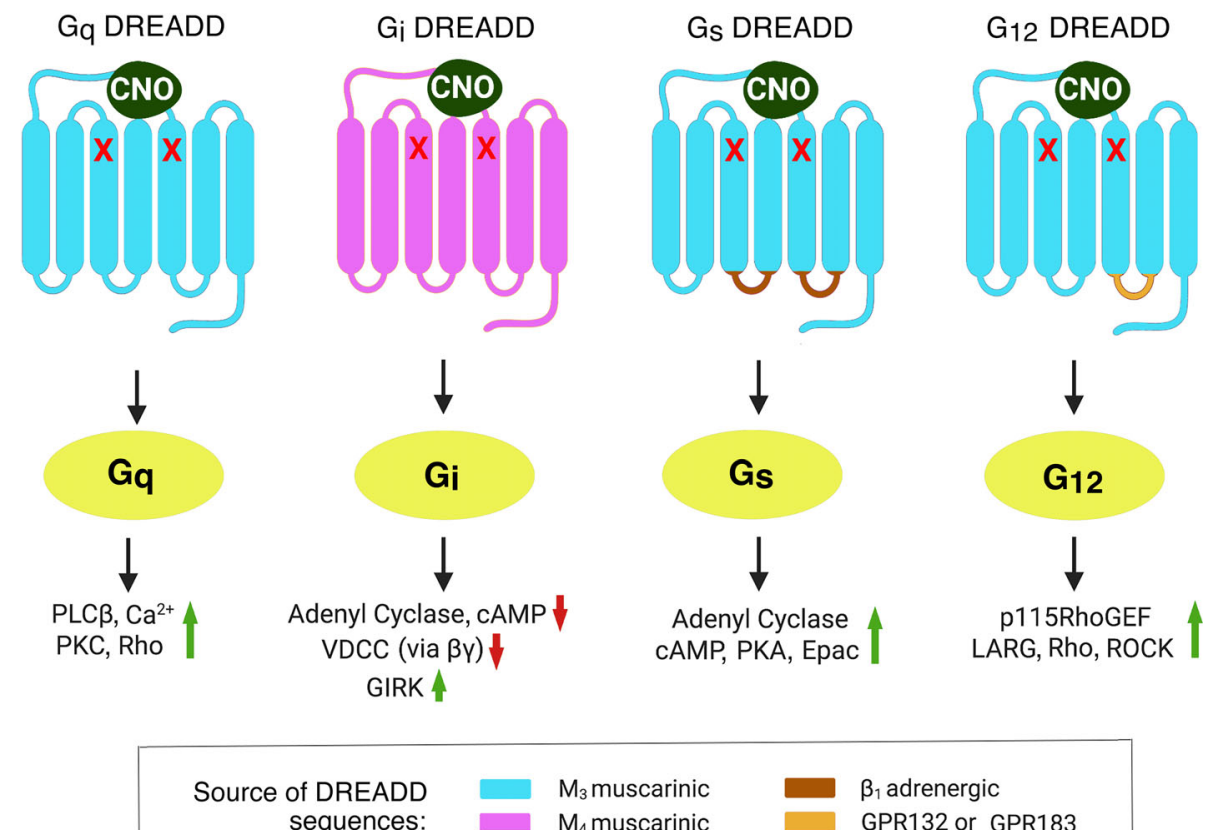

$\beta_{1}$ adrenergic

GPR132 or GPR183

FIGURE 1 | Structural properties of DREADDs able to selectively activate each of the four major subclasses of heterotrimeric G proteins. The DREADDs shown here are all mutant muscarinic acetylcholine receptors that can be activated by CNO with high potency and efficacy. The red $\mathrm{x}$ marks indicate point mutations that prevent acetylcholine from activating these designer receptors (5). The $G_{q}$ and $G_{i} D R E A D D s$ were developed by Armbruster et al. (5). The $G_{s}$ and $G_{12}$ DREADDs were generated in the laboratories of Jürgen Wess (6) and Asuka Inoue (7), respectively. Activated $G$ protein $\alpha$-subunits stimulate or inhibit distinct intracellular effector enzymes or ion channels. This figure represents a modified version of Figure 1 published in (8). Epac, exchange protein activated by cAMP; GIRK, G-proteinregulated inward-rectifier potassium channel; LARG, Leukemia-Associated RhoGEF; PLC $\beta$, phospholipase CB; PKA, protein kinase A; PKC, protein kinase C; RhoGEF, Rho guanine nucleotide exchange factor; ROCK, Rho-associated coiled-coil-containing protein kinase; VDCC, voltage-dependent $\mathrm{Ca}^{2+-}{ }^{2+}$ hannel.

DREADDs that are selectively linked to each of the four major classes of heterotrimeric $G$ proteins have become available (5-7) (Figure 1).

Since the development of the first DREADDs in 2007 (5), these new designer receptors have emerged as very useful tools to study GPCR physiology. The in vivo use of DREADD technology offers several major advantages that help understand the cellular mechanisms underlying GPCR-mediated metabolic effects. DREADDs with different coupling properties can be expressed in a cell type-specific fashion, for example by generating transgenic mice or by using virus-based delivery techniques. CNO treatment of these mutant mice then leads to the selective stimulation of a particular GPCR signaling pathway only in DREADD-expressing cells. Thus, this approach makes it possible to assess the in vivo consequences of activating distinct GPCR signaling pathways in specific cell types. Such studies cannot be performed by traditional pharmacological approaches.

During the past decade, we and other laboratories generated many mutant mouse strains that express different DREADDs in distinct cell types that are critical for maintaining glucose and energy homeostasis [for recent reviews, see $(8,12)$ ]. These include $\beta$ - and $\alpha$-cells of the endocrine pancreas, adipocytes, hepatocytes, skeletal muscle cells, and distinct neuronal subpopulations of the hypothalamus. In most cases, $\mathrm{CNO}$ treatment of the various DREADD mutant mice resulted in robust metabolic phenotypes. In many cases, the observed phenotypic changes were more pronounced when mice were maintained on a high-fat (obesogenic) diet which causes impaired glucose tolerance and insulin sensitivity, two hallmarks of type 2 diabetes (T2D) $(8,12)$. To demonstrate that DREADD-mediated responses do not diminish over time, several studies also examined the metabolic effects of chronic CNO treatment [e.g (13-15)].

The metabolic phenotypes observed after CNO treatment of the different DREADD mutant mouse lines led to the identification of several distinct GPCR signaling pathways critical for the maintenance of glucose and/or energy homeostasis $(8,12)$. For example, studies with DREADD mutant mice suggest that agents able to disrupt hepatocyte $G_{q}$, $\mathrm{G}_{\mathrm{s}}$, or $\mathrm{G}_{\mathrm{i}}$ signaling may prove useful to restore euglycemia under pathophysiological conditions associated with enhanced hepatic glucose production (e.g. in T2D) (16-18). Drugs capable of selectively activating $G_{s}$ or $G_{i}$ signaling in adipocytes may prove beneficial to restore impaired energy, lipid, and glucose homeostasis in T2D and obesity $(14,15)$. Agents capable of activating $G_{s}$ or $G_{q}$ in $\beta$-cells are predicted to stimulate glucoseinduced insulin release and to promote $\beta$-cell replication when applied chronically $(6,13)$. Compounds that can enhance $\mathrm{G}_{\mathrm{q}}$ signaling in skeletal muscle tissues could become clinically relevant for stimulating glucose uptake by skeletal muscle in 
T2D (19). Finally, DREADD studies also strongly suggest that GPCR-based drugs able to modulate the activity of metabolically important neurons of the hypothalamus (e.g. AgRP and POMC neurons) may prove beneficial for the treatment of severe disorders of glucose and energy homeostasis [for a recent review, see (12)].

A major challenge that remains is to identify endogenous GPCRs that are highly expressed in a specific cell type of interest and that display the desired $G$ protein coupling properties, as suggested by the analysis of DREADD mutant mice. Because of the relatively low cellular expression levels of most GPCRs, combined with the lack of highly specific GPCR antibodies, the identification and quantification of GPCR protein levels in specific tissues or cell types is a daunting task. On the other hand, the detection of GPCR transcript levels represents a more straightforward approach and can be achieved by applying qPCR- and RNA-seq-based techniques to cells isolated from humans or animal models (20). Moreover, highly selective agonists or antagonist are not available for a large number of GPCRs. However, the development of such agents will be instrumental for exploiting the new insights gained from the analysis of DREADD mutant mice for therapeutic purposes.

It is also important to verify that the signaling pathways that mediate beneficial metabolic effects in mice are conserved in human tissues. To address this issue, follow-up studies with human primary cells are recommended as a key first step. It has been shown that GPCR expression levels/profiles can undergo significant changes under altered metabolic states and/or pathophysiological conditions [see, for example (14)]. This phenomenon needs to be taken into account during the

\section{REFERENCES}

1. Lagerström MC, Schiöth HB. Structural Diversity of G Protein-Coupled Receptors and Significance for Drug Discovery. Nat Rev Drug Discov (2008) 7:339-57. doi: 10.1038/nrd2518

2. Fredriksson R, Lagerström MC, Lundin LG, Schiöth HB. The G-ProteinCoupled Receptors in the Human Genome Form Five Main Families. Phylogenetic Analysis, Paralogon Groups, and Fingerprints. Mol Pharmacol (2003) 63:1256-72. doi: 10.1124/mol.63.6.1256

3. Sriram K, Insel PA. G Protein-Coupled Receptors as Targets for Approved Drugs: How Many Targets and How Many Drugs? Mol Pharmacol (2018) 93:251-8. doi: 10.1124/mol.117.111062

4. Wettschureck N, Offermanns S. Mammalian G Proteins and Their Cell Type Specific Functions. Physiol Rev (2005) 85:1159-204. doi: 10.1152/ physrev.00003.2005

5. Armbruster BN, Li X, Pausch MH, Herlitze S, Roth BL. Evolving the Lock to Fit the Key to Create a Family of G Protein-Coupled Receptors Potently Activated by an Inert Ligand. Proc Natl Acad Sci USA (2007) 104:5163-8. doi: 10.1073/ pnas.0700293104

6. Guettier JM, Gautam D, Scarselli M, Ruiz de Azua I, Li JH, Rosemond E, et al. A Chemical-Genetic Approach to Study G Protein Regulation of Beta Cell Function In Vivo. Proc Natl Acad Sci USA (2009) 106:19197-202. doi: 10.1073/pnas.0906593106

7. Inoue A, Raimondi F, Kadji FMN, Singh G, Kishi T, Uwamizu A, et al. Illuminating G-Protein-Coupling Selectivity of GPCRs. Cell (2019) 177:193347. doi: 10.1016/j.cell.2019.04.044

8. Wang L, Zhu L, Meister J, Bone DBJ, Pydi SP, Rossi M, et al. Use of DREADD Technology to Identify Novel Targets for Antidiabetic Drugs. Annu Rev Pharmacol Toxicol (2021) 61:421-40. doi: 10.1146/annurev-pharmtox-030220-121042 development of novel ligands aimed at targeting specific GPCR signaling pathways for therapeutic purposes. It should also be noted that activated DREADDs can recruit $\beta$-arrestins $(21,22)$, raising the possibility that DREADD activation may also cause changes in cell metabolism via $\beta$-arrestin-dependent pathways. For this reason, phenotypic analysis of mutant mice that express distinct DREADDs in specific celll types that lack $\beta$-arrestins (23) are likely to facilitate the interpretation of in vivo DREADD studies.

In conclusion, the use of DREADD technology has greatly advanced our knowledge about the important metabolic roles of specific GPCR signaling pathways in maintaining proper glucose and energy homeostasis in vivo. It is likely that the novel insights gained from these chemogenetic studies will eventually lead to the development of novel classes of drugs that will prove highly efficacious for the treatment of several severe metabolic disorders.

\section{AUTHOR CONTRIBUTIONS}

The author confirms being the sole contributor of this work and has approved it for publication.

\section{FUNDING}

The author's own research cited in this article was supported by the Intramural Research Program of the NIH, NIDDK, Bethesda, Maryland, USA.

9. Regard JB, Sato IT, Coughlin SR. Anatomical Profiling of G ProteinCoupled Receptor Expression. Cell (2008) 135:561-71. doi: 10.1016/j.cell. 2008.08.040

10. Nagai Y, Miyakawa N, Takuwa H, Hori Y, Oyama K, Ji B, et al Deschloroclozapine, a Potent and Selective Chemogenetic Actuator Enables Rapid Neuronal and Behavioral Modulations in Mice and Monkeys. Nat Neurosci (2020) 23:1157-67. doi: 10.1038/s41593-020-0661-3

11. Thompson KJ, Khajehali E, Bradley SJ, Navarrete JS, Huang XP, Slocum S, et al. DREADD Agonist 21 Is an Effective Agonist for Muscarinic-Based DREADDs In Vitro and In Vivo. ACS Pharmacol Transl Sci (2018) 1:61-72. doi: 10.1021/acsptsci.8b00012

12. Meister J, Wang L, Pydi SP, Wess J. Chemogenetic Approaches to Identify Metabolically Important GPCR Signaling Pathways: Therapeutic Implications. J Neurochem (2021) 32:112-29. doi: 10.1111/jnc.15314

13. Jain S, Ruiz de Azua I, Lu H, White MF, Guettier JM, Wess J. Chronic Activation of a Designer G(q)-Coupled Receptor Improves Beta Cell Function. J Clin Invest (2013) 123:1750-62. doi: 10.1172/JCI66432

14. Wang L, Pydi SP, Zhu L, Barella LF, Cui Y, Gavrilova O, et al. Adipocyte G(i) Signaling is Essential for Maintaining Whole-Body Glucose Homeostasis and Insulin Sensitivity. Nat Commun (2020) 11:2995. doi: 10.1038/s41467-02016756-x

15. Wang L, Pydi SP, Cui Y, Zhu L, Meister J, Gavrilova O, et al. Selective Activation of Gs Signaling in Adipocytes Causes Striking Metabolic Improvements in Mice. Mol Metab (2019) 27:83-91. doi: 10.1016/ j.molmet.2019.06.018

16. Li JH, Jain S, McMillin SM, Cui Y, Gautam D, Sakamoto W, et al. A Novel Experimental Strategy to Assess the Metabolic Effects of Selective Activation of a G(q)-Coupled Receptor in Hepatocytes In Vivo. Endocrinology (2013) 154:3539-51. doi: 10.1210/en.2012-2127 
17. AkhmedovD, Mendoza-Rodriguez MG, Rajendran K, Rossi M, Wess J, Berdeaux R. Gs-DREADD Knock-In Mice for Tissue-Specific, Temporal Stimulation of Cyclic AMP Signaling. Mol Cell Biol (2017) 37:e00584-16. doi: 10.1128/MCB.00584-16

18. Rossi M, Zhu L, McMillin SM, Pydi SP, Jain S, Wang L, et al. Hepatic Gi Signaling Regulates Whole-Body Glucose Homeostasis. J Clin Invest (2018) 128:746-59. doi: 10.1172/JCI94505

19. Bone DBJ, Meister J, Knudsen JR, Dattaroy D, Cohen A, Lee R, et al. Skeletal Muscle-Specific Activation of Gq Signaling Maintains Glucose Homeostasis. Diabetes (2019) 68:1341-52. doi: 10.2337/db18-0796

20. Sriram K, Wiley SZ, Moyung K, Gorr MW, Salmerón C, Marucut J, et al. Detection and Quantification of GPCR mRNA: An Assessment and Implications of Data From High-Content Methods. ACS Omega (2019) 4:17048-59. doi: 10.1021/acsomega.9b02811

21. Alvarez-Curto E, Prihandoko R, Tautermann CS, Zwier JM, Pediani JD, Lohse MJ, et al. Developing Chemical Genetic Approaches to Explore G ProteinCoupled Receptor Function: Validation of the Use of a Receptor Activated Solely by Synthetic Ligand (RASSL). Mol Pharmacol (2011) 80:1033-46. doi: 10.1124/mol.111.074674
22. Hu J, Stern M, Gimenez LE, Wanka L, Zhu L, Rossi M, et al. A G ProteinBiased Designer G Protein-Coupled Receptor Useful for Studying the Physiological Relevance of Gq/11-Dependent Signaling Pathways. J Biol Chem (2016) 291:7809-20. doi: 10.1074/jbc.M115.702282

23. Pydi SP, Barella LF, Meister J, Wess J. Key Metabolic Functions of $\beta$-Arrestins: Studies With Novel Mouse Models. Trends Endocrinol Metabol: TEM (2021) 32:118-29. doi: 10.1016/j.tem.2020.11.008

Conflict of Interest: The author declares that the research was conducted in the absence of any commercial or financial relationships that could be construed as a potential conflict of interest.

Copyright (C) 2021 Wess. This is an open-access article distributed under the terms of the Creative Commons Attribution License (CC BY). The use, distribution or reproduction in other forums is permitted, provided the original author(s) and the copyright owner(s) are credited and that the original publication in this journal is cited, in accordance with accepted academic practice. No use, distribution or reproduction is permitted which does not comply with these terms. 